\title{
Personalised computational cardiology: Patient-specific modelling in cardiac mechanics and biomaterial injection therapies for myocardial infarction
}

\author{
Kevin L. Sack ${ }^{1} \cdot$ Neil H. Davies ${ }^{2} \cdot$ Julius M. Guccione $^{3} \cdot$ Thomas Franz $^{1}$
}

Published online: 1 February 2016

(c) The Author(s) 2016. This article is published with open access at Springerlink.com

\begin{abstract}
Predictive computational modelling in biomedical research offers the potential to integrate diverse data, uncover biological mechanisms that are not easily accessible through experimental methods and expose gaps in knowledge requiring further research. Recent developments in computing and diagnostic technologies have initiated the advancement of computational models in terms of complexity and specificity. Consequently, computational modelling can increasingly be utilised as enabling and complementing modality in the clinic-with medical decisions and interventions being personalised. Myocardial infarction and heart failure are amongst the leading causes of death globally despite optimal modern treatment. The development of novel MI therapies is challenging and may be greatly facilitated through predictive modelling. Here, we review the advances in patient-specific modelling of cardiac mechanics, distinguishing specificity in cardiac geometry, myofibre architecture and mechanical tissue properties. Thereafter, the focus narrows to the mechanics of the infarcted heart and treatment of myocardial infarction with particular attention on intramyocardial biomaterial delivery.
\end{abstract}

Thomas Franz

thomas.franz@uct.ac.za

1 Division of Biomedical Engineering, Department of Human Biology, Faculty of Health Sciences, University of Cape Town, Private Bag X3, 7935 Observatory, South Africa

2 Cardiovascular Research Unit, MRC IUCHRU, Chris Barnard Division of Cardiothoracic Surgery, University of Cape Town, Observatory, South Africa

3 Department of Surgery, University of California at San Francisco, San Francisco, CA, USA
Keywords Cardiac disease · Finite-element method . Subject specific - Computational model - Ischaemic heart disease $\cdot$ Heart failure

\section{Introduction}

Cardiovascular diseases are the single leading cause of death worldwide, accounting for $30 \%$ of all human mortality [1]. Despite recent advances in pharmaceutical, surgical, device and tissue-engineered therapy strategies, cardiovascular diseases remain one of the most costly, common and deadly medical conditions. Since predicted mortality of cardiovascular diseases is projected to increase, it is expected to remain the leading cause of death globally $[1,2]$.

Computational models can provide a unique framework for assessing efficacy of therapy approaches with relatively low resources: Therapeutic parameters can be easily modified and assessed in multiple concurrent in silico experiments, and computational sensitivity studies are easily conducted to optimise treatment efficacy. Advancing research and technologies have sparked a great deal of interest in integrating FE models into the clinical environment. This is becoming more achievable each year, making it likely that computational models will serve as the first line of the screening for future therapies in the years to come [3].

Reliable computational models can also provide a richer source of information for clinical decision support and treatment planning. Patient- and subject-specific computational modelling has been increasing at an exponential rate (Fig. 1a), and sources of patient-specific genetic, anatomical and physiological information are already being incorporated in the clinical workflow [4-6]. 
Fig. 1 Number of yearly publications of peer-reviewed journal articles a with "patientspecific" or "subject-specific" contained in the title and $\mathbf{b}$ for finite-element-based studies focusing on cardiac ventricular mechanics. Source: Thomson Reuters ISI Web of Knowledge ${ }^{\circledR}$ and PubMed ${ }^{\circledR}$ databases, January 2016
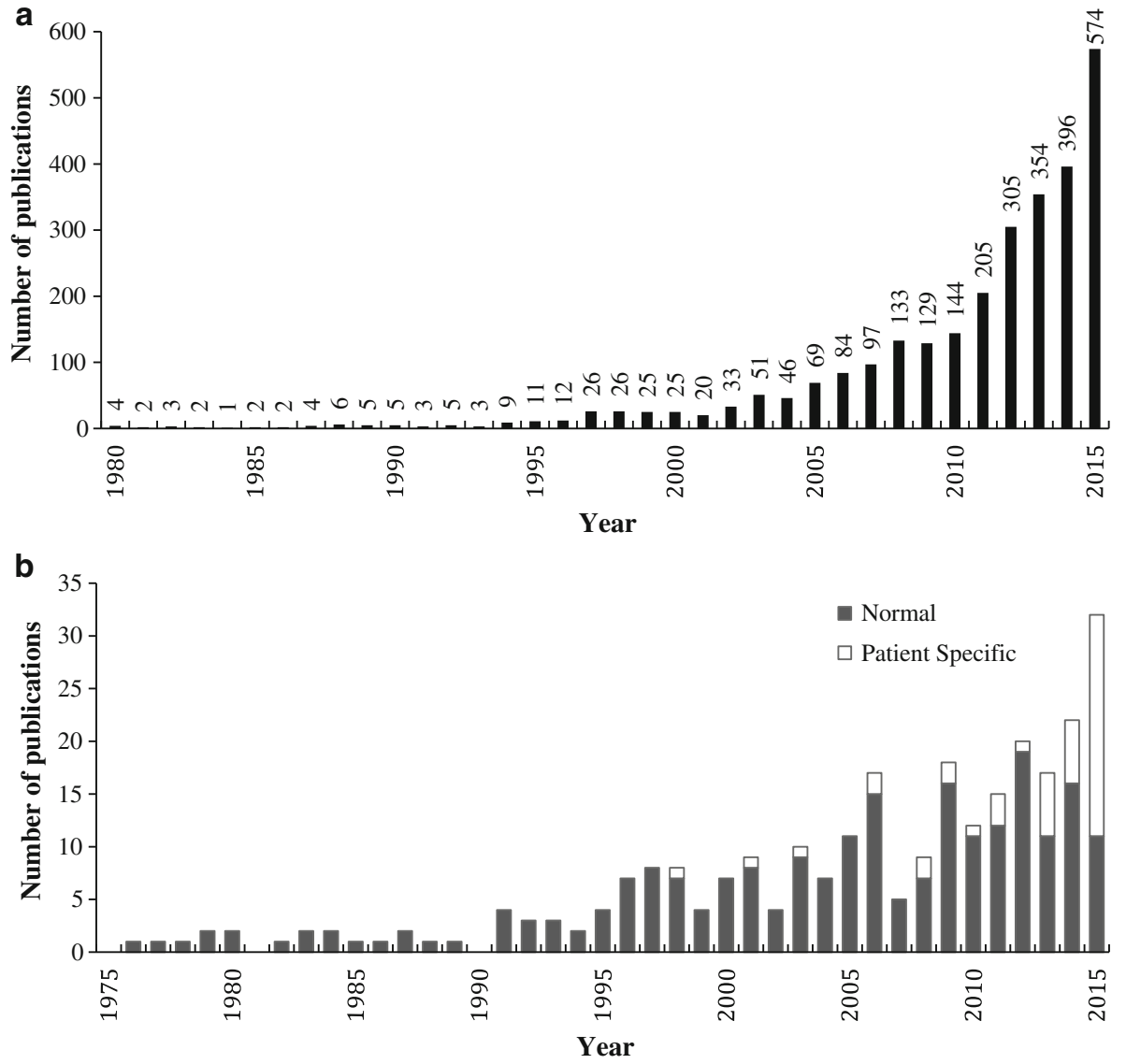

This review aims at contextualising the advances and challenges of patient-specific computational modelling with particular focus on cardiac and infarct mechanics and the translation of therapeutic concepts, based on intramyocardial biomaterial injections, for the myocardial infarction (MI) and infarct-induced heart failure (HF). The developments in subject- and patient-specific modelling are detailed with focus on cardiac geometries, myofibre architecture and the constitutive properties of cardiac tissue. Thereafter, the focus narrows on computational modelling of infarct mechanics and therapies for MI, in particular intramyocardial biomaterial injection.

\section{Patient-specific modelling of cardiac mechanics}

\section{Cardiac geometries}

Anatomical simplification needs to balance model accuracy and computational demands. Until recently, this motivated the use of simplified left ventricular (LV) geometries introduced by various groups [7-9] as the primary computational tool for investigating cardiac mechanics. The use of patient-specific realistic geometries has, however, become prevalent in computational models (Fig. 1b). This shift towards realistic geometries is indicative of the goal to create more representative computational models for use in clinical decision support.

The first three-dimensional patient-specific computational geometry of a heart was introduced by Okajima et al. [10] to study electrical activation. It took over two decades for deformable computational finite-element (FE) approaches to incorporate realistic heart geometries [11]. Nielsen et al. [12] presented a realistic biventricular model that was novel for its accurate geometric description and definition of myofibre orientation. Stevens et al. [13] extended the model to account, in part, for the four valves. Since then, realistic geometrical models have become increasingly popular. The Living Heart Project recently developed the first full heart model that features a four-chamber human heart geometry with the four valves and the connecting large vessels [14].

To date, patient-specific cardiac geometries have been introduced as representative cases as proof of concept that a given computational approach can be applied in a patientspecific framework. Extending the concept to computational studies with a large number of patient-specific geometries could generate statistically meaningful results 
for a patient population. An alternative approach is to utilise a statistically averaged geometry that is representative of a patient population [15].

\section{Myofibre architecture}

The myofibre orientation has a critical influence on cardiac mechanics and electrophysiology. However, the description of myofibre orientation is a highly intricate and sophisticated task, which has been the subject of substantial historical disagreement [16-18]. The intricacy stems from the complex multiscale branching and merging of cardiac myocytes at microscopic scale, creating anisotropy at tissue level that changes dramatically throughout the structure. An accurate numerical portrayal of the myofibre architecture needs to incorporate the one-dimensional directional tangent of the myofibre and the description of the fibre sheets [18-20] which influences both passive and active material behaviour.

In recent work, two methods are predominant in describing the myofibre orientation in patient-specific cardiac models: Rule-based reconstructions and fibre orientation derived from diffusion tensor magnetic resonance imaging (DTMRI). Rule-based approaches typically describe the fibre orientation analytically or through aggregated experimental data, whereby a dense fibre orientation field is constructed through interpolation functions $[21,22]$. This has recently been cast in the form of a boundary value problem, whereby the fibre orientation is prescribed along the surfaces of the ventricular structure and solved for throughout the geometry [23]. Rule-based reconstructions can be advantageous in their application to highly irregular geometries and their efficient implementation. In DTMRI approaches, the myofibre orientation is calculated from the eigenvectors of diffusion tensors. Due to the challenges of in vivo cardiac DTMRI, this method is often limited to a single post mortem data set. In this case, the derived fibre orientations are projected (or mapped) onto other subject- or patient-specific geometries obtained from computed tomography (CT) or magnetic resonance imaging (MRI) [24, 25]. Toussaint et al. [26] recently captured in vivo patient-specific myofibre orientation data and integrated these data in other LV models of other patients. This approach involved diffeomorphic data transformations between a realistic geometry and the prolate spheroidal coordinate system.

Considering the sensitivity of FE predictions to variations in fibre orientation [27-29], it is preferable to incorporate patient-specific DTMRI data whenever possible. DTMRI is, however, still limited as the diffusion tensor characterises only the mean myofibre structure in a voxel volume. Improved accuracy may be achieved by increased spatial resolution of the DTMRI scan or by including a dispersion parameter accounting for the deviation of the fibre orientation within in a voxel. Whereas homogenous dispersion has been considered in modelling myocardial tissue [30], dispersion at voxel scale has not yet been considered. Toussaint et al. [26] in vivo DTMRI analysis is the most advanced approach at present. No computational models have investigated cardiac function using truly individual patient-specific fibre orientation.

\section{Constitutive properties}

The first constitutive relationship for passive myocardial behaviour, in the form of an exponential strain energy formulation, has been credited to by Yuan-Cheng Fung [31-33]. The first invariant-based constitutive model was described by Humphrey and Yin [34], introducing an additional "fibrespecific" term to account for the material anisotropy, although limited to transverse isotropy [32]. Costa et al. [35] developed an extended orthotropic formulation featuring a fibre-specific coordinate system and principal material stiffness along the fibre, sheet and normal directions. With minor modifications, the formulations are commonly represented as strain energy density function [36, 37]:

$\Psi=\frac{1}{2}\left(C e^{Q}-1\right)+A_{\text {incomp }}$.

Here $Q$ is a function of the material strains (usually GreenLagrange), often given as

$$
\begin{aligned}
Q= & b_{f f} E_{f f}^{2}+b_{s s} E_{s s}^{2}+b_{n n} E_{n n}^{2}+\frac{b_{n f}}{2}\left(E_{n f}^{2}+E_{f n}^{2}\right) \\
& +\frac{b_{n s}}{2}\left(E_{n s}^{2}+E_{s n}^{2}\right)+\frac{b_{s f}}{2}\left(E_{s f}^{2}+E_{f s}^{2}\right),
\end{aligned}
$$

where $E_{i j}$ are the components of the right Cauchy-Green deformation tensor in local fibre coordinates and $b_{i j}$ are the corresponding material parameters. The strain energy function in the exponential form can also be constructed by considering the invariants $I_{i}$ of the right Cauchy-Green strain tensor [38]:

$$
\begin{aligned}
\Psi= & \frac{a}{2 b} e^{b\left(I_{1}-3\right)}+\sum_{i=f, s} \frac{a_{i}}{2 b_{i}}\left\{e^{b_{i}\left(I_{4 i}-1\right)^{2}}-1\right\} \\
& +\frac{a_{f s}}{2 b_{f s}}\left\{e^{b_{f s} I_{8 f s}^{2}}-1\right\}+A_{\text {incomp }},
\end{aligned}
$$

The notation and material parameters detailed by Holzapfel and Ogden [38] have become the most widely used form of a passive material law for cardiac mechanics, often recalibrated with new material parameters [22, 39, 40]. The incompressibility of the material is handled through a penalty function $A_{\text {incomp }}$, of which multiple variations exist, and which is often implemented through mixed formulation methods, splitting the deformation into isochoric and deviatoric components. 
The incorporation of active tension into a mathematical description to capture the contractile behaviour of the heart is a significant task. The most common approach, introduced by Guccione et al. [41], relies on additive contribution of the active stress to the overall material stress, typically along the local fibre orientation. Active tension can be constructed using various physiologically meaningful parameters, which has been employed by many studies [14, 39, 42, 43]. Another emerging approach involves multiplicative decomposition of the tensor gradient of deformation [44-46], in a similar fashion to the theory of volumetric growth. Multiplicative decomposition is more mathematically robust, whereas the additive approach can capture physiological phenomena more meaningfully. The latter is due to a more flexible formulation that allows for parameter calibration on a tensor component level [44, 45]. Contractile material behaviour can be coupled within an electromechanical framework, whereby a more realistic excitation-contraction pattern is incorporated into the model. Over the last decade, this multi-physics coupling has been introduced with great success in various computational models [47-53].

It is impossible to meaningfully determine the three-dimensional patient-specific material properties from ventricular pressure-volume relationships alone [54]. To remedy this, the identification of suitable values for the constitutive parameters (sometimes called calibration) often utilises additional data. In vitro biaxial and shear stress-strain experiments $[55,56]$ on cardiac tissue have been used to calibrate numerous constitutive laws. The reliability of in vitro experiments may be questionable due to tissue damage or disruption in the process of extraction [57]. Inclusion of in vivo data in material calibration provides a more realistic mechanical environment for loading and deformation [58]. Obtaining these stress-strain data from magnetic resonance electrography (MRE) or tagged MRI provides additional advantages whereby patient-specific information can be captured into the constitutive law through optimisation approaches [24, 54, 59-61]. This approach has recently been extended to additionally estimate infarct material parameters $[62,63]$. Considering the anatomical variability amongst patients, it becomes increasingly attractive to calibrate material laws for geometrically consistent in vivo data, i.e., local stress-strain data for the same geometry and fibre distribution-an inherently patient- or subject-specific process that can easily be adopted to handle cardiac pathologies, e.g., MI.

\section{Modelling of MI treatments}

Noninvasive assessment of the heart after MI is essential for optimal treatment. Local wall stress, in particular, can be a key factor in assessing cardiac function and predict
post-MI effects, yet wall stress cannot be measured systematically and quantitatively with clinical modalities [64]. Imaging techniques provide high accuracy information regarding the strain distribution in the heart, yet cannot provide local stress information. Laplace's law, used to estimate cardiac wall stress, makes considerable assumptions with respect to the cardiac structure and provides considerably different results to anatomically accurate FE models [65].

FE models have been labelled as the most versatile approach for quantitatively predicting myocardial stress and strain distributions [66, 67]. The effects of MI on structure and function of the heart have received increasing attention for FE modelling. The understanding of the aforementioned is essential when developing a treatment to restore cardiac function and to attenuate adverse post-infarct remodelling. Simulating $\mathrm{MI}$ in silico allows the influence on heart to be directly quantified [46, 68-71], providing deeper insight into the underlying mechanisms involved. For example, by complementing a study on dosage efficacy of the ACE inhibitor ramipril, FE models showed that apical wall stress is an independent predictor of ventricular remodelling [72].

Surgical ventricular restoration (SVR) has been the focus of several computational studies [73-77]. The most recent SVR studies [75, 76] provide examples for how FE models with increased complexity can contribute to elucidating physiological processes and guiding treatment development. For the treatment of MI, Guccione et al. [78] investigated a "myosplint" device aimed at restraining the epicardium to prevent remodelling. Wenk et al. [79] explored the Acorn CorCap cardiac support device as treatment for dilated cardiomyopathy. Another ventricular restoration approach relies on the Parachute (C) device [80] which was subject of a patient-specific FE study indicating that the reduction in end-diastolic wall stress underlies the therapeutic benefit [43]. Mitral valve regurgitation, a secondary adverse condition resulting from ventricular remodelling, often following $\mathrm{MI}$, has received recent attention with increasingly sophisticated FE models (Fig. 2) [81-84].

\section{Modelling of material injection therapies for MI}

There has been significant recent interest in intramyocardial biomaterial injections as therapy for MI, whereby predominantly the infarcted region of the heart is injected with a biomaterial which aims to inhibit the adverse remodelling that leads to $\mathrm{HF}$. Injectable biomaterials are showing promise in preclinical studies [85-92], resulting in a range of improvements to cardiac repair, with respect to wall thickness, ejection fraction and ventricular volume. 


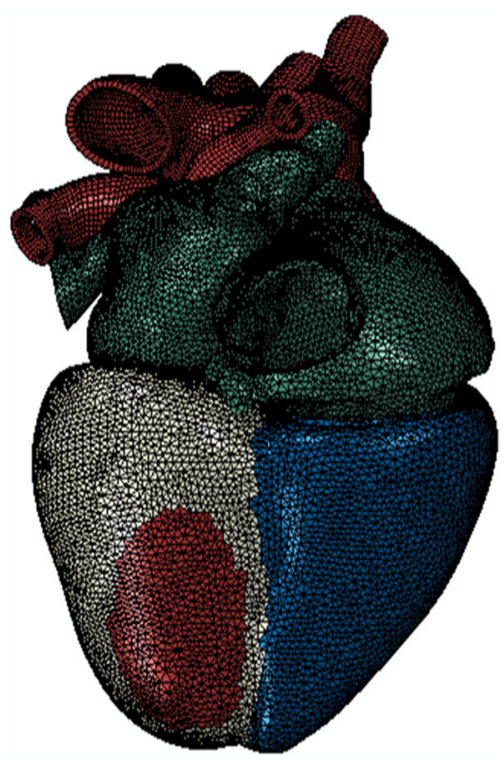

Fig. 2 Patient-specific FE model for investigation of treatment of mitral valve regurgitation. Reproduced with permission from Baillargeon et al. [115]

Further research on the specific mechanisms by which these biomaterials improve cardiac function is needed to aid the development of more effective treatment.

Research into cardiac injection therapy has become diverse due to the choice of injectable material and the delivery method from a range of viable options [93, 94]. Due to this, the representation of intramyocardial biomaterial injectates in computational models relies on either homogenisation approaches, whereby the injected material is averaged in the description of the myocardium wall, or through geometric approaches, whereby the injections are considered separate inclusions embedded within the wall.
Homogenisation techniques have shown consistently that bulking the myocardium with non-contractile material was sufficient to offset post-MI geometric changes and, consequently decrease stress in the myocardial wall (Fig. 3) [95]. Material injections that result in increased stiffness to the infarct region have also been shown to lower stresses in the infarcted and healthy regions of the heart in subject-specific ovine LV FE models [67] (Fig. 4) and for idealised ellipsoid LV models [96]. Improvements to cardiac function seen in the subject-specific ovine FE model such as wall thickening and increased ejection fraction [67] are consistent with in vitro and in vivo experiments [97]. In a combined experimental and computational study, Kichula et al. [98] used an ellipsoidal LV FE model (Fig. 5) to quantify the anisotropic increase in stiffness due to hydrogel injection and the reduction in local and global wall stresses. Dorsey et al. [92] developed subject-specific porcine LV FE models from cardiac MRI data to estimate the in vivo diastolic material properties of infarcted tissue with therapeutic hyaluronic acid-based hydrogel injections.

For more viscous injectable materials or when the mechanical effects of the injectate at a microstructural level are being investigated [99-102], modelling the injected material as a discrete inclusion more meaningfully represents the mechanical considerations. Computational studies have consistently shown the beneficial impact to cardiac function from material injections of this nature. Wenk et al. [99] studied in an ellipsoidal LV FE model the optimal distribution of multiple spherical injectates. Kortsmit et al. [101] and Miller et al. [100] modelled the striated and bulk injectate distribution observed preclinically [89, 90, 97], (Fig. 6a, b), as discrete sheet-like structures embedded within the myocardium in a canine
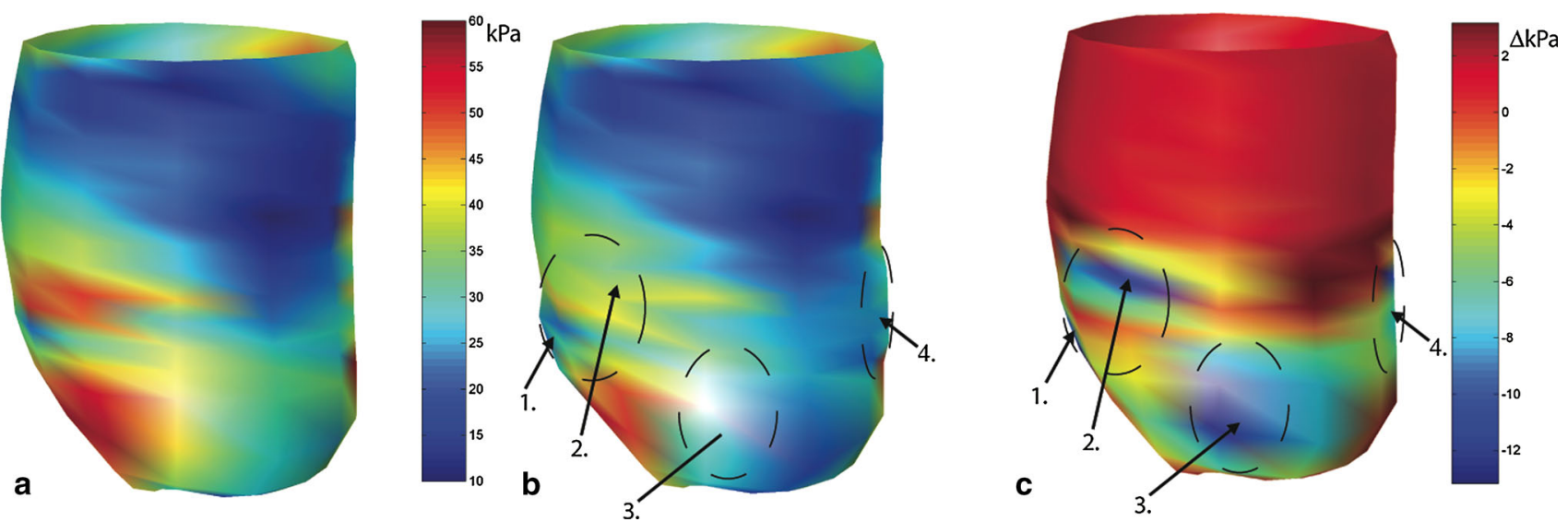

Fig. 3 FE prediction of midwall fibre stress in an ovine left ventricle with anteroapical infarct without treatment (a) and with simulated intramyocardial delivery $4.4 \mathrm{~mL}$ of biomaterial in four infarct border zone locations indicated by arrows (b). Difference of midwall fibre stress between the untreated infarct and treated infarct that demonstrates the location of stress reduction in relation to the injection sites (arrows) (c). Adapted with permission from Wall et al. [95] 
biventricular model and a human LV model, respectively. These sheet-like hydrogel inclusions were shown to better improve cardiac performance in the ischaemic infarct stage, but bulk-like injectates were shown to be better at improving LV function at the remodelling stage, complementing an experimental study in rats which investigated the effects of delayed gel-injection therapy [89]. Sirry et al. [103] presented a more realistic microstructurally detailed geometry of a striated polyethylene glycol hydrogel injectate in an infarcted rat heart, similar to Fig. 6c.

Residual stress in the cardiac wall due to material injections has only recently been considered. Using a patient-specific LV FE model based on MRI data of a patient with HF, ischaemic cardiomyopathy and hypertension, Lee et al. [104] revealed a complex regional stress field in vicinity of the a set of spherical hydrogel injectates located equidistant between the base and the apex of the LV (Fig. 7). These first results warrant further investigation into the local changes the injections cause to tissue and

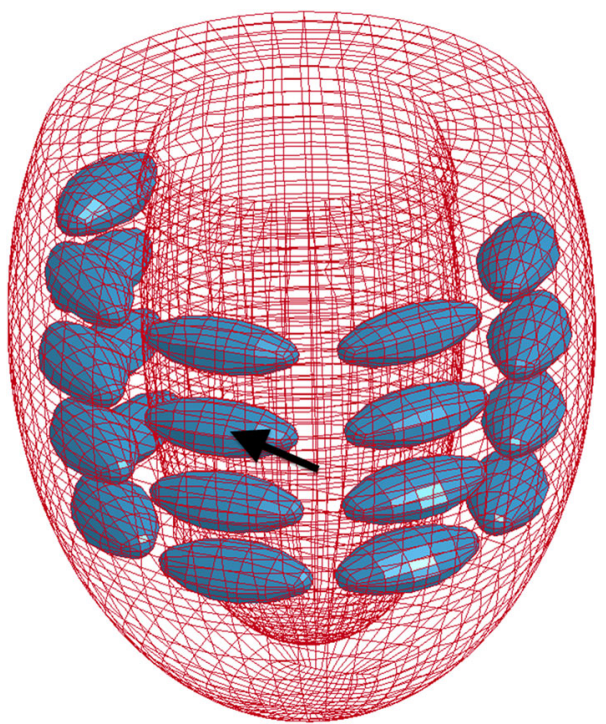

Fig. 5 Ellipsoidal LV FE model with 20 intramyocardial hydrogel injectates. Adapted with permission from Kichula et al. [98]
Fig. 4 Contour plots of fibre stress in the lateral wall of an ovine left ventricle with untreated infarct at end diastole (a) and end systole (b), and after treatment by delivery of $2.6 \mathrm{~mL}$ of a calcium hydroxyapatitebased tissue filler distributed over 20 evenly spaced injections at end diastole (c) and end systole (d). (Colour scales of the end diastole panels are the same, and colour scales of the end systole panels are the same). Adapted with permission from Wenk et al. [67]

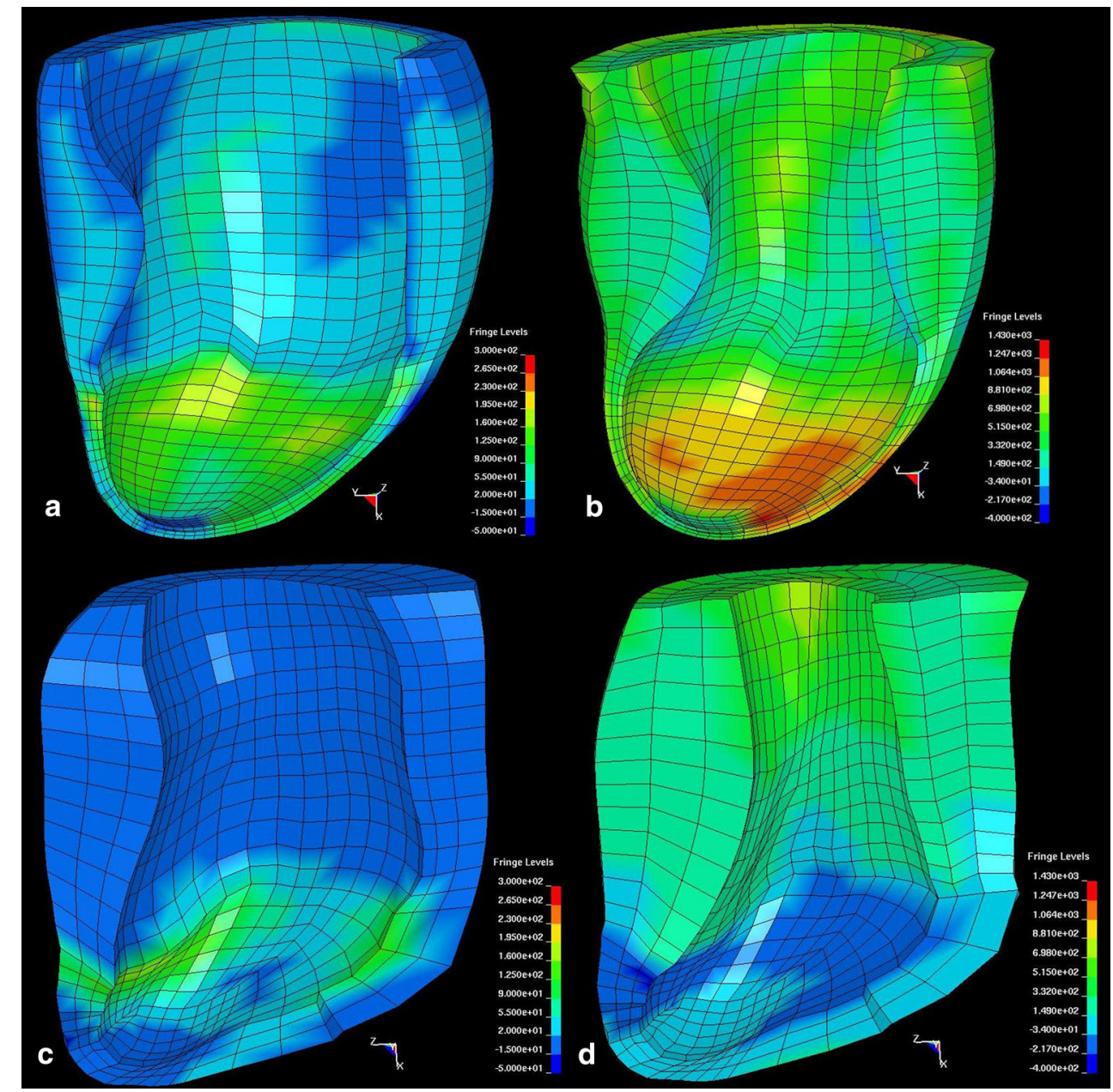


fibre structure, as well as the mechanisms responsible for the clinically observed reduction in global stress [105].

Lee et al. [106] investigated a combination treatment of biomaterial injections and coronary artery bypass grafting with patient-specific models developed from MRI data of three patients suffering with HF. Simulating a longitudinal study with pre-treatment and three- and six-months posttreatment time points revealed a more uniform distribution and $35 \%$ reduction in myofibre stress throughout the LV.

\section{Discussion}

Advances in patient-specific computational cardiac mechanics over the last decade have been significant in almost every aspect. The quality of imaging and segmentation techniques coupled with increasing computational resources have allowed for unprecedented growth. Geometrically realistic multi-physics models are becoming the new standard of computational cardiology. As structural and functional data of the heart become more easily available, the calibration and validation of these models becomes more reliable.

Patient-specific models hold promise for personalising diagnosis, treatment planning and therapy design. The example of SVR emphasises that interventions based on accurate patient-specific information have clear advantages over treatments that are not personalised. Large-cohort patient-specific computational studies, simulating treatments in silico, will also be able to unlock novel and statistically meaningful findings for entire patient populations-something that cannot be achieved with a small number of computational models. The ability to reuse computational models, perturb parameters and perform
Fig. 6 Histological

micrographs demonstrating the distribution of a polyethylene glycol hydrogel (appearing in pink) delivered immediately (a) and seven days (b) after infarct induction in rat hearts (nuclei appear blue, bar represents $50 \mu \mathrm{m}$ ). Reproduced with permission from Kadner et al. [89]. Reconstructed 3D geometry of a polyethylene glycol hydrogel injectate with microstructural details reconstructed from histological sections in a biventricular rat heart geometry (c) (injectate shown in pink)
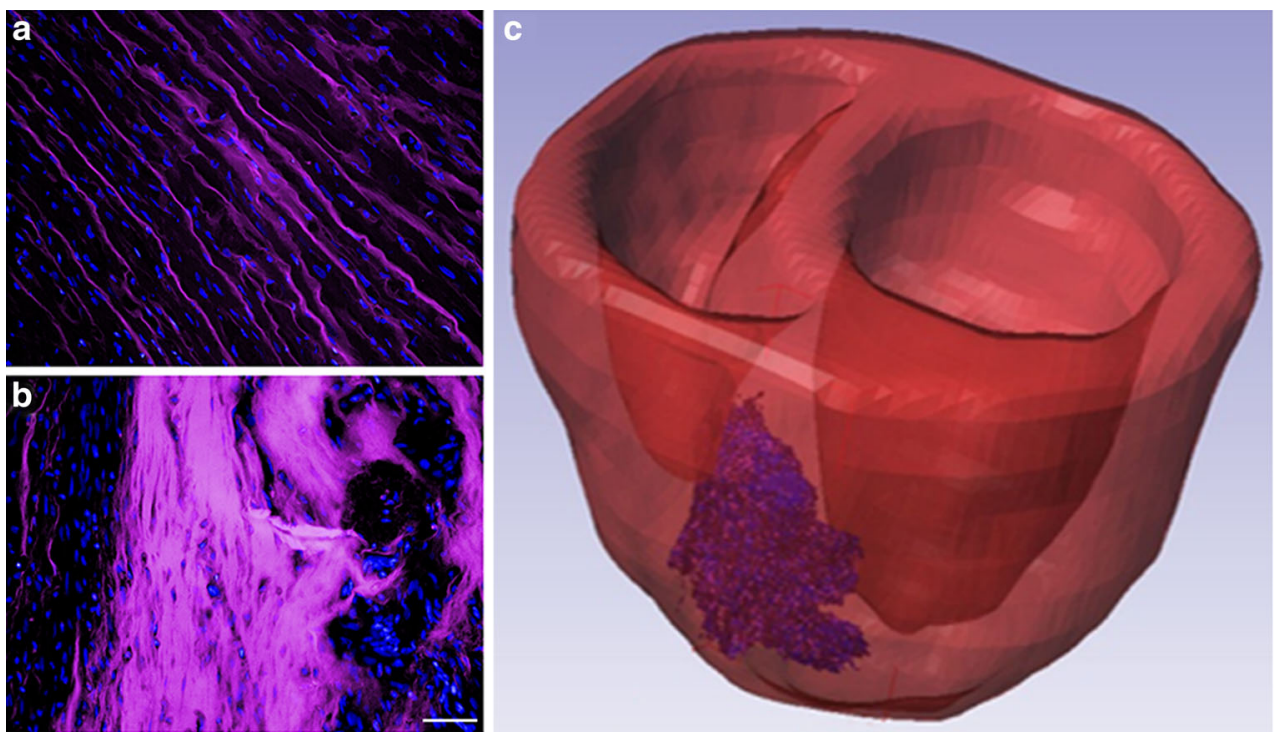

Fig. 7 Patient-specific LV FE model with 12 ellipsoidal hydrogel injectates located equidistant between the base and the apex. Adapted with permission from Lee et al. [104]
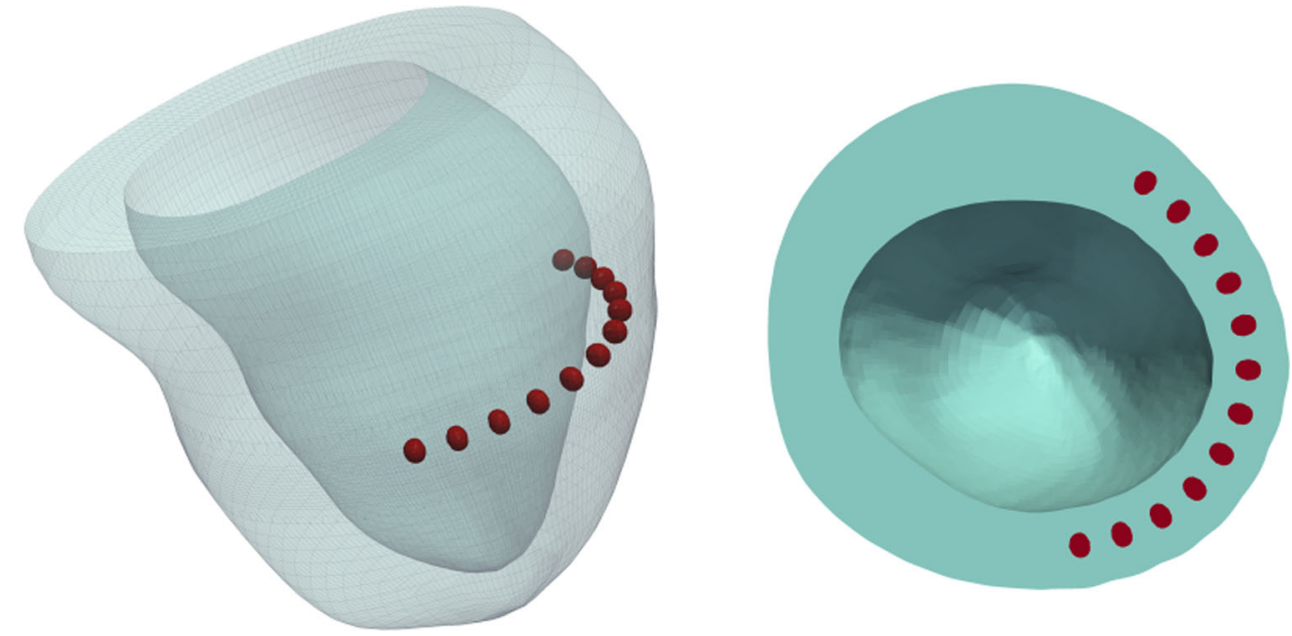
sensitivity studies will not only provide an unprecedented wealth of information in the aid of therapy design but can also accelerate the translation of therapy approaches into the clinical setting.

Despite these advantages, there has yet to be a single high-resolution patient-specific computational cardiac model, constructed and calibrated using data from a single patient. Accounting for patient-specific myofibre structure and calibrating material laws using comprehensive in vivo data are still largely lacking in computational models investigating cardiac mechanics.

While recent computational research on biomaterial injection MI therapies has made substantial progress, more work is needed to further elucidate the mechanisms underlying the benefits observed. The local and global changes in myocardial tissue structure after MI, including necrosis, fibrosis and scar formation, and the representation in computational models are one area that need to receive increased attention. Pending availability of experimental data, advanced numerical methods to model growth [107109] and tissue healing [110] may be adaptable to computationally describe MI-related "reverse" growth and remodelling. This will allow to study in more detail the effects of biomaterial injectates on tissue changes which may provide additional therapeutic cues. A related challenge is the realistic representation of in situ injectate geometries, in particular when biomaterial infiltrates the myocardium at microscopic level [89, 90, 97]. Also yet unconsidered in computational models are injection therapies with mechanobiological targets such as fibroblast reprogramming $[111,112]$ and stem cell therapies [113, 114].

\section{Conclusions}

Realistic predictive patient-specific computational models require comprehensive in vivo data for calibration and validation. In the context of cardiac diseases and therapies, current in vivo imaging technologies are not yet advanced enough to provide such patient-specific data as part of the clinical diagnostic modalities. Until cutting-edge modalities such as in vivo cardiac DTMRI become more available in the clinic routine, the pursuit of fully subject-specific computational modelling remains limited to preclinical research, where a richer resource of in vivo and ex vivo data can be utilised. Subject-specific computational modelling can, however, offer great potential to complement experimental research and can play a crucial role in advancing biomaterial injection therapies for MI.

Acknowledgments The authors thank Pamela Derish in the Department of Surgery, University of California San Francisco for proofreading the manuscript. Financial support was provided by the South African National Research Foundation (to TF and KS), the Oppenheimer Memorial Trust (to KS), the South African Medical Research Council (to NHD) and the National Institutes of Health (to JMG; Grants R01HL-077921 and R01HL-118627 and U01HL119578). Any opinion, findings and conclusions or recommendations expressed in this material are those of the authors, and therefore, the NRF does not accept any liability in this regard thereto.

Open Access This article is distributed under the terms of the Creative Commons Attribution 4.0 International License (http://crea tivecommons.org/licenses/by/4.0/), which permits unrestricted use, distribution, and reproduction in any medium, provided you give appropriate credit to the original author(s) and the source, provide a link to the Creative Commons license, and indicate if changes were made.

\section{References}

1. WHO (2011) Global status report on noncommunicable diseases 2010: Description of the global burden of NCDs, their risk factors and determinants. World Health Organization, Geneva

2. Mathers CD, Loncar D (2006) Projections of global mortality and burden of disease from 2002 to 2030. PLoS Med 3(11):e442. doi:10.1371/journal.pmed.0030442

3. Trayanova NA (2011) Whole-heart modeling: applications to cardiac electrophysiology and electromechanics. Circ Res 108(1):113-128. doi:10.1161/circresaha.110.223610

4. Meier G, Besson R, Nanz A, Safai S, Lomax AJ (2015) Independent dose calculations for commissioning, quality assurance and dose reconstruction of PBS proton therapy. Phys Med Biol 60(7):2819-2836. doi:10.1088/0031-9155/60/7/2819

5. Balasso A, Bauer JS, Liebig T, Dorn F, Zimmer C, Liepsch D, Prothmann S (2015) Evaluation of intra-aneurysmal hemodynamics after flow diverter placement in a patient-specific aneurysm model. Biorheology 51(6):341-354. doi:10.3233/bir-14019

6. Goyal N, Stulberg SD (2015) Evaluating the precision of preoperative planning in patient specific instrumentation: can a single MRI yield different preoperative plans? The Journal of arthroplasty 30(7):1250-1253. doi:10.1016/j.arth.2015.02.021

7. Arts T, Reneman RS, Veenstra PC (1979) A model of the mechanics of the left ventricle. Ann Biomed Eng 7(3-4):299-318

8. Streeter DD Jr, Hanna WT (1973) Engineering mechanics for successive states in canine left ventricular myocardium. II. Fiber angle and sarcomere length. Circ Res 33(6):656-664

9. Janz RF, Grimm AF (1972) Finite-element model for the mechanical behavior of the left ventricle. Prediction of deformation in the potassium-arrested rat heart. Circ Res 30(2):244-252

10. Okajima M, Fujino T, Kobayashi T, Yamada K (1968) Computer simulation of the propagation process in excitation of the ventricles. Circ Res 23(2):203-211

11. Wei D (1997) Whole-heart modeling: progress, principles and applications. Prog Biophys Mol Biol 67(1):17-66

12. Nielsen PM, Le Grice IJ, Smaill BH, Hunter PJ (1991) Mathematical model of geometry and fibrous structure of the heart. Am J Physiol 260(4 Pt 2):H1365-1378

13. Stevens C, Remme E, LeGrice I, Hunter P (2003) Ventricular mechanics in diastole: material parameter sensitivity. J Biomech 36(5):737-748

14. Baillargeon B, Rebelo N, Fox DD, Taylor RL, Kuhl E (2014) The living heart project: a robust and integrative simulator for human heart function. Eur J Mech A Solids 48:38-47. doi:10. 1016/j.euromechsol.2014.04.001 
15. Young AA, Frangi AF (2009) Computational cardiac atlases: from patient to population and back. Exp Physiol 94(5):578-596. doi:10.1113/expphysiol.2008.044081

16. Buckberg G, Mahajan A, Saleh S, Hoffman JI, Coghlan C (2008) Structure and function relationships of the helical ventricular myocardial band. J Thorac Cardiovasc Surg 136(3):578-589. doi:10.1016/j.jtcvs.2007.10.088 (589 e571-511)

17. Gilbert SH, Benson AP, Li P, Holden AV (2007) Regional localisation of left ventricular sheet structure: integration with current models of cardiac fibre, sheet and band structure. Eur J Cardio-thorac Surg 32(2):231-249. doi:10.1016/j.ejcts.2007.03. 032

18. Pope AJ, Sands GB, Smaill BH, LeGrice IJ (2008) Three-dimensional transmural organization of perimysial collagen in the heart. Am J Physiol Heart Circ Physiol 295(3):H1243-H1252. doi:10.1152/ajpheart.00484.2008

19. LeGrice I, Hunter P, Young A, Small B (2001) The architecture of the heart: a data-based model. Philos Trans R Soc A 359(1783):1217-1232. doi:10.1098/rsta.2001.0827

20. Lombaert H, Peyrat JM, Croisille P, Rapacchi S, Fanton L, Cheriet F, Clarysse P, Magnin I, Delingette H, Ayache N (2012) Human atlas of the cardiac fiber architecture: study on a healthy population. IEEE Trans Med Imaging 31(7):1436-1447. doi:10. 1109/TMI.2012.2192743

21. Wang HM, Gao H, Luo XY, Berry C, Griffith BE, Ogden RW, Wang TJ (2013) Structure-based finite strain modelling of the human left ventricle in diastole. Int J Numer Methods Biomed Eng 29(1):83-103. doi:10.1002/cnm.2497

22. Genet M, Lee LC, Nguyen R, Haraldsson H, Acevedo-Bolton G, Zhang Z, Ge L, Ordovas K, Kozerke S, Guccione JM (2014) Distribution of normal human left ventricular myofiber stress at end-diastole and end-systole-a target for in silico design of heart failure treatments. J Appl Physiol 117(2):142-152. doi:10.1152/ japplphysiol.00255.2014

23. Wong J, Kuhl E (2014) Generating fibre orientation maps in human heart models using Poisson interpolation. Comput Methods Biomech Biomed Eng 17(11):1217-1226. doi:10.1080/ 10255842.2012.739167

24. Wang VY, Lam HI, Ennis DB, Cowan BR, Young AA, Nash MP (2009) Modelling passive diastolic mechanics with quantitative MRI of cardiac structure and function. Med Image Anal 13(5):773-784. doi:10.1016/j.media.2009.07.006

25. Krishnamurthy A, Villongco CT, Chuang J, Frank LR, Nigam V, Belezzuoli E, Stark P, Krummen DE, Narayan S, Omens JH, McCulloch AD, Kerckhoffs RC (2013) Patient-specific models of cardiac biomechanics. J Comput Phys 244:4-21. doi:10.1016/ j.jcp.2012.09.015

26. Toussaint N, Stoeck CT, Schaeffter T, Kozerke S, Sermesant M, Batchelor PG (2013) In vivo human cardiac fibre architecture estimation using shape-based diffusion tensor processing. Med Image Anal 17(8):1243-1255. doi:10.1016/j.media.2013.02.008

27. Bovendeerd PH, Arts T, Huyghe JM, van Campen DH, Reneman RS (1992) Dependence of local left ventricular wall mechanics on myocardial fiber orientation: a model study. J Biomech 25(10):1129-1140. doi:10.1016/0021-9290(92)900 69-D

28. Chen J, Liu W, Zhang H, Lacy L, Yang X, Song SK, Wickline SA, Yu X (2005) Regional ventricular wall thickening reflects changes in cardiac fiber and sheet structure during contraction: quantification with diffusion tensor MRI. Am J Physiol Heart Circ Physiol 289(5):H1898-1907. doi:10.1152/ajpheart.00041. 2005

29. Sack KL, Skatulla S, Sansour C (2015) Biological tissue mechanics with fibres modelled as one-dimensional Cosserat continua. Applications to cardiac tissue. Int J Solids Struct. doi:10.1016/j.ijsolstr.2015.11.009
30. Eriksson TS, Prassl AJ, Plank G, Holzapfel GA (2013) Modeling the dispersion in electromechanically coupled myocardium. Int J Numer Methods Biomed Eng 29(11):1267-1284. doi:10. $1002 / \mathrm{cnm} .2575$

31. Holzapfel GA, Gasser TC, Ogden RW (2000) A new constitutive framework for arterial wall mechanics and a comparative study of material models. J Elast 61(1-3):1-48. doi:10.1023/A: 1010835316564

32. Humphrey JD (2003) Review paper: continuum biomechanics of soft biological tissues. Proc R Soc A Math Phys Eng Sci 459(2029):3-46. doi:10.1098/rspa.2002.1060

33. Sacks MS (2000) Biaxial mechanical evaluation of planar biological materials. J Elast 61(1-3):199-246. doi:10.1023/A: 1010917028671

34. Humphrey JD, Yin FC (1987) A new constitutive formulation for characterizing the mechanical behavior of soft tissues. Biophys J 52(4):563-570. doi:10.1016/S0006-3495(87)83245-9

35. Costa KD, Holmes JW, McCulloch AD (2001) Modelling cardiac mechanical properties in three dimensions. Philos Trans $\mathrm{R}$ Soc A 359(1783):1233-1250. doi:10.1098/rsta.2001.0828

36. Kerckhoffs RC, Faris OP, Bovendeerd PH, Prinzen FW, Smits K, McVeigh ER, Arts T (2003) Timing of depolarization and contraction in the paced canine left ventricle: model and experiment. J Cardiovasc Electrophysiol 14(10 Suppl):S188195

37. Usyk T, McCulloch A (2003) Computational methods for soft tissue biomechanics. In: Holzapfel G, Ogden R (eds) Biomechanics of soft tissue in cardiovascular systems, vol 441. International Centre for Mechanical Sciences. Springer Vienna, pp 273-342. doi:10.1007/978-3-7091-2736-0_7

38. Holzapfel GA, Ogden RW (2009) Constitutive modelling of passive myocardium: a structurally based framework for material characterization. Philos Trans Ser A Math Phys Eng Sci 367(1902):3445-3475. doi:10.1098/rsta.2009.0091

39. Göktepe S, Acharya SNS, Wong J, Kuhl E (2011) Computational modeling of passive myocardium. Int $\mathrm{J}$ Numer Methods Biomed Eng 27(1):1-12. doi:10.1002/cnm.1402

40. Nikou A, Dorsey SM, McGarvey JR, Gorman JH 3rd, Burdick JA, Pilla JJ, Gorman RC, Wenk JF (2015) Computational modeling of healthy myocardium in diastole. Ann Biomed Eng. doi:10.1007/s10439-015-1403-7

41. Guccione JM, Waldman LK, McCulloch AD (1993) Mechanics of active contraction in cardiac muscle: part II-cylindrical models of the systolic left ventricle. J Biomech Eng 115(1): $82-90$

42. Usyk TP, Mazhari R, McCulloch AD (2000) Effect of laminar orthotropic myofiber architecture on regional stress and strain in the canine left ventricle. J Elasticity 61(1-3):143-164. doi:10. 1023/A:1010883920374

43. Lee LC, Ge L, Zhang Z, Pease M, Nikolic SD, Mishra R, Ratcliffe MB, Guccione JM (2014) Patient-specific finite element modeling of the Cardiokinetix Parachute ${ }^{\circledR}$ device: effects on left ventricular wall stress and function. Med Biol Eng Comput 52(6):557-566. doi:10.1007/s11517-014-1159-5

44. Ambrosi D, Pezzuto S (2012) Active stress vs. active strain in mechanobiology: constitutive issues. J Elast 107(2):199-212. doi:10.1007/s10659-011-9351-4

45. Rossi S, Ruiz-Baier R, Pavarino LF, Quarteroni A (2012) Orthotropic active strain models for the numerical simulation of cardiac biomechanics. Int $\mathrm{J}$ Numer Methods Biomed Eng 28(6-7):761-788. doi:10.1002/cnm.2473

46. Berberoğlu E, Solmaz HO, Göktepe S (2014) Computational modeling of coupled cardiac electromechanics incorporating cardiac dysfunctions. Eur J Mech A Solids 48:60-73

47. Göktepe S, Kuhl E (2009) Electromechanics of the heart: a unified approach to the strongly coupled excitation-contraction 
problem. Comput Mech 45(2-3):227-243. doi:10.1007/s00466009-0434-Z

48. Lafortune P, Aris R, Vazquez M, Houzeaux G (2012) Coupled electromechanical model of the heart: parallel finite element formulation. Int J Numer Methods Biomed Eng 28(1):72-86. doi:10.1002/Cnm.1494

49. Sainte-Marie J, Chapelle D, Cimrman R, Sorine M (2006) Modeling and estimation of the cardiac electromechanical activity. Comput Struct 84(28):1743-1759. doi:10.1016/j.comp struc.2006.05.003

50. Kerckhoffs RC, Bovendeerd PH, Kotte JC, Prinzen FW, Smits K, Arts T (2003) Homogeneity of cardiac contraction despite physiological asynchrony of depolarization: a model study. Ann Biomed Eng 31(5):536-547. doi:10.1114/1.1566447

51. Nordsletten DA, Niederer SA, Nash MP, Hunter PJ, Smith NP (2011) Coupling multi-physics models to cardiac mechanics. Prog Biophys Mol Biol 104(1-3):77-88. doi:10.1016/j.pbio molbio.2009.11.001

52. Niederer SA, Plank G, Chinchapatnam P, Ginks M, Lamata P, Rhode KS, Rinaldi CA, Razavi R, Smith NP (2011) Lengthdependent tension in the failing heart and the efficacy of cardiac resynchronization therapy. Cardiovasc Res 89(2):336-343. doi:10.1093/cvr/cvq318

53. Rosolen AM, Ordas S, Vazquez M, Frangi AF (2006) Numerical schemes for the simulation of three-dimensional cardiac electrical propagation in patient-specific ventricular geometries. Paper presented at the European conference on computational fluid dynamics ECCOMAS CFD 2006

54. Sun K, Stander N, Jhun CS, Zhang Z, Suzuki T, Wang GY, Saeed M, Wallace AW, Tseng EE, Baker AJ, Saloner D, Einstein DR, Ratcliffe MB, Guccione JM (2009) A computationally efficient formal optimization of regional myocardial contractility in a sheep with left ventricular aneurysm. J Biomech Eng 131(11):111001. doi:10.1115/1.3148464

55. Demer LL, Yin FC (1983) Passive biaxial mechanical properties of isolated canine myocardium. J Physiol 339:615-630

56. Dokos S, Smaill BH, Young AA, LeGrice IJ (2002) Shear properties of passive ventricular myocardium. Am J Physiol Heart Circ Physiol 283(6):H2650-2659. doi:10.1152/ajpheart. 00111.2002

57. Remme EW, Hunter PJ, Smiseth O, Stevens C, Rabben SI, Skulstad H, Angelsen BB (2004) Development of an in vivo method for determining material properties of passive myocardium. J Biomech 37(5):669-678. doi:10.1016/j.jbiomech. 2003.09.023

58. Zervantonakis IK, Fung-Kee-Fung SD, Lee WN, Konofagou EE (2007) A novel, view-independent method for strain mapping in myocardial elastography: eliminating angle and centroid dependence. Phys Med Biol 52(14):4063-4080. doi:10.1088/ 0031-9155/52/14/004

59. Xi J, Lamata P, Niederer S, Land S, Shi W, Zhuang X, Ourselin S, Duckett SG, Shetty AK, Rinaldi CA, Rueckert D, Razavi R, Smith NP (2013) The estimation of patient-specific cardiac diastolic functions from clinical measurements. Med Image Anal 17(2):133-146. doi:10.1016/j.media.2012.08.001

60. Sermesant M, Moireau P, Camara O, Sainte-Marie J, Andriantsimiavona R, Cimrman R, Hill DLG, Chapelle D, Razavi R (2006) Cardiac function estimation from MRI using a heart model and data assimilation: advances and difficulties. Med Image Anal 10(4):642-656

61. Lee WN, Ingrassia CM, Fung-Kee-Fung SD, Costa KD, Holmes JW, Konofagou EE (2007) Theoretical quality assessment of myocardial elastography with in vivo validation. IEEE Trans Ultrason Ferroelectr Freq Control 54(11):2233-2245

62. Mojsejenko D, McGarvey JR, Dorsey SM, Gorman JH 3rd, Burdick JA, Pilla JJ, Gorman RC, Wenk JF (2015) Estimating passive mechanical properties in a myocardial infarction using MRI and finite element simulations. Biomech Model Mechanobiol 14(3):633-647. doi:10.1007/s10237-014-0627-z

63. McGarvey JR, Mojsejenko D, Dorsey SM, Nikou A, Burdick JA, Gorman JH III, Jackson BM, Pilla JJ, Gorman RC, Wenk JF (2015) Temporal changes in infarct material properties: an in vivo assessment using magnetic resonance imaging and finite element simulations. Ann Thorac Surg 100(2):582-590. doi:10. 1016/j.athoracsur.2015.03.015

64. Dorri F, Niederer PF, Lunkenheimer PP (2006) A finite element model of the human left ventricular systole. Comput Methods Biomech Biomed Eng 9(5):319-341. doi:10.1080/10255840600 960546

65. Zhang Z, Tendulkar A, Sun K, Saloner DA, Wallace AW, Ge L, Guccione JM, Ratcliffe MB (2011) Comparison of the YoungLaplace law and finite element based calculation of ventricular wall stress: implications for postinfarct and surgical ventricular remodeling. Ann Thorac Surg 91(1):150-156. doi:10.1016/j. athoracsur.2010.06.132

66. Shimkunas R, Zhang Z, Wenk JF, Soleimani M, Khazalpour M, Acevedo-Bolton G, Wang G, Saloner D, Mishra R, Wallace AW (2013) Left ventricular myocardial contractility is depressed in the borderzone after posterolateral myocardial infarction. Ann Thorac Surg 95(5):1619-1625

67. Wenk JF, Eslami P, Zhang Z, Xu C, Kuhl E, Gorman JH 3rd, Robb JD, Ratcliffe MB, Gorman RC, Guccione JM (2011) A novel method for quantifying the in vivo mechanical effect of material injected into a myocardial infarction. Ann Thorac Surg 92(3):935-941. doi:10.1016/j.athoracsur.2011.04.089

68. Bogen DK, Rabinowitz SA, Needleman A, McMahon TA, Abelmann WH (1980) An analysis of the mechanical disadvantage of myocardial infarction in the canine left ventricle. Circ Res 47(5):728-741

69. Mazhari R, Omens JH, Covell JW, McCulloch AD (2000) Structural basis of regional dysfunction in acutely ischemic myocardium. Cardiovasc Res 47(2):284-293. doi:10.1016/ S0008-6363(00)00089-4

70. Guccione JM, Moonly SM, Moustakidis P, Costa KD, Moulton MJ, Ratcliffe MB, Pasque MK (2001) Mechanism underlying mechanical dysfunction in the border zone of left ventricular aneurysm: a finite element model study. Ann Thorac Surg 71(2):654-662

71. Kerckhoffs RC, Neal ML, Gu Q, Bassingthwaighte JB, Omens JH, McCulloch AD (2007) Coupling of a 3D finite element model of cardiac ventricular mechanics to lumped systems models of the systemic and pulmonic circulation. Ann Biomed Eng 35(1):1-18. doi:10.1007/s10439-006-9212-7

72. Aikawa Y, Rohde L, Plehn J, Greaves SC, Menapace F, Arnold MO, Rouleau JL, Pfeffer MA, Lee RT, Solomon SD (2001) Regional wall stress predicts ventricular remodeling after anteroseptal myocardial infarction in the Healing and Early Afterload Reducing Trial (HEART): an echocardiography-based structural analysis. Am Heart J 141(2):234-242

73. Ratcliffe MB, Hong J, Salahieh A, Ruch S, Wallace AW (1998) The effect of ventricular volume reduction surgery in the dilated, poorly contractile left ventricle: a simple finite element analysis. J Thorac Cardiovasc Surg 116(4):566-577

74. Dang AB, Guccione JM, Zhang P, Wallace AW, Gorman RC, Gorman JH 3rd, Ratcliffe MB (2005) Effect of ventricular size and patch stiffness in surgical anterior ventricular restoration: a finite element model study. Ann Thorac Surg 79(1):185-193. doi:10.1016/j.athoracsur.2004.06.007

75. Lee LC, Wenk JF, Zhong L, Klepach D, Zhang Z, Ge L, Ratcliffe MB, Zohdi TI, Hsu E, Navia JL, Kassab GS, Guccione JM (2013) Analysis of patient-specific surgical ventricular restoration: importance of an ellipsoidal left ventricular geometry for 
diastolic and systolic function. J Appl Physiol 115(1):136-144. doi:10.1152/japplphysiol.00662.2012 (1985)

76. Zhong L, Su Y, Gobeawan L, Sola S, Tan RS, Navia JL, Ghista DN, Chua T, Guccione J, Kassab GS (2011) Impact of surgical ventricular restoration on ventricular shape, wall stress, and function in heart failure patients. Am J Physiol Heart Circ Physiol 300(5):H1653-H1660. doi:10.1152/ajpheart.00021.2011

77. Athanasuleas CL, Stanley AW Jr, Buckberg GD, Dor V, DiDonato M, Blackstone EH (2001) Surgical anterior ventricular endocardial restoration (SAVER) in the dilated remodeled ventricle after anterior myocardial infarction. RESTORE group. reconstructive endoventricular surgery, returning torsion original radius elliptical shape to the LV. J Am Coll Cardiol 37(5):1199-1209

78. Guccione JM, Salahieh A, Moonly SM, Kortsmit J, Wallace AW, Ratcliffe MB (2003) Myosplint decreases wall stress without depressing function in the failing heart: a finite element model study. Ann Thorac Surg 76(4):1171-1180 (discussion 1180)

79. Wenk JF, Ge L, Zhang Z, Mojsejenko D, Potter DD, Tseng EE, Guccione JM, Ratcliffe MB (2013) Biventricular finite element modeling of the Acorn CorCap Cardiac Support Device on a failing heart. Ann Thorac Surg 95(6):2022-2027. doi:10.1016/j. athoracsur.2013.02.032

80. Mazzaferri EL Jr, Gradinac S, Sagic D, Otasevic P, Hasan AK, Goff TL, Sievert H, Wunderlich N, Nikolic SD, Abraham WT (2012) Percutaneous left ventricular partitioning in patients with chronic heart failure and a prior anterior myocardial infarction: results of the percutaneous ventricular restoration in chronic heart failure patients trial. Am Heart J 163(5):812-820. doi:10. 1016/j.ahj.2012.02.013 (e811)

81. Rim Y, McPherson DD, Kim H (2014) Mitral valve function following ischemic cardiomyopathy: a biomechanical perspective. Bio-Med Mater Eng 24(1):7-13. doi:10.3233/bme-130777

82. Wong VM, Wenk JF, Zhang Z, Cheng G, Acevedo-Bolton G, Burger M, Saloner DA, Wallace AW, Guccione JM, Ratcliffe MB, Ge L (2012) The effect of mitral annuloplasty shape in ischemic mitral regurgitation: a finite element simulation. Ann Thorac Surg 93(3):776-782. doi:10.1016/j.athoracsur.2011.08. 080

83. Carrick R, Ge L, Lee LC, Zhang Z, Mishra R, Axel L, Guccione JM, Grossi EA, Ratcliffe MB (2012) Patient-specific finite element-based analysis of ventricular myofiber stress after Coapsys: importance of residual stress. Ann Thorac Surg 93(6):1964-1971. doi:10.1016/j.athoracsur.2012.03.001

84. Wenk JF, Zhang Z, Cheng G, Malhotra D, Acevedo-Bolton G, Burger M, Suzuki T, Saloner DA, Wallace AW, Guccione JM, Ratcliffe MB (2010) First finite element model of the left ventricle with mitral valve: insights into ischemic mitral regurgitation. Ann Thorac Surg 89(5):1546-1553. doi:10.1016/j. athoracsur.2010.02.036

85. Atkins BZ, Hueman MT, Meuchel J, Hutcheson KA, Glower DD, Taylor DA (1999) Cellular cardiomyoplasty improves diastolic properties of injured heart. J Surg Res 85(2):234-242. doi:10.1006/jsre.1999.5681

86. Christman KL, Fok HH, Sievers RE, Fang Q, Lee RJ (2004) Fibrin glue alone and skeletal myoblasts in a fibrin scaffold preserve cardiac function after myocardial infarction. Tissue Eng 10(3-4):403-409. doi:10.1089/107632704323061762

87. Landa N, Miller L, Feinberg MS, Holbova R, Shachar M, Freeman I, Cohen S, Leor J (2008) Effect of injectable alginate implant on cardiac remodeling and function after recent and old infarcts in rat. Circulation 117(11):1388-1396. doi:10.1161/ CIRCULATIONAHA.107.727420

88. Plotkin M, Vaibavi SR, Rufaihah AJ, Nithya V, Wang J, Shachaf Y, Kofidis T, Seliktar D (2014) The effect of matrix stiffness of injectable hydrogels on the preservation of cardiac function after a heart attack. Biomaterials 35(5):1429-1438. doi:10.1016/j.biomaterials.2013.10.058

89. Kadner K, Dobner S, Franz T, Bezuidenhout D, Sirry MS, Zilla P, Davies NH (2012) The beneficial effects of deferred delivery on the efficiency of hydrogel therapy post myocardial infarction. Biomaterials 33(7):2060-2066. doi:10.1016/j.biomaterials.2011. 11.031

90. Dobner S, Bezuidenhout D, Govender P, Zilla P, Davies N (2009) A synthetic non-degradable polyethylene glycol hydrogel retards adverse post-infarct left ventricular remodeling. J Cardiac Fail 15(7):629-636

91. Sabbah HN, Wang M, Gupta RC, Rastogi S, Ilsar I, Sabbah MS, Kohli S, Helgerson S, Lee RJ (2013) Augmentation of left ventricular wall thickness with alginate hydrogel implants improves left ventricular function and prevents progressive remodeling in dogs with chronic heart failure. JACC Heart Fail 1(3):252-258

92. Dorsey SM, McGarvey JR, Wang H, Nikou A, Arama L, Koomalsingh KJ, Kondo N, Gorman JH III, Pilla JJ, Gorman RC, Wenk JF, Burdick JA (2015) MRI evaluation of injectable hyaluronic acid-based hydrogel therapy to limit ventricular remodeling after myocardial infarction. Biomaterials 69:65-75. doi:10.1016/j.biomaterials.2015.08.011

93. Nelson DM, Ma Z, Fujimoto KL, Hashizume R, Wagner WR (2011) Intra-myocardial biomaterial injection therapy in the treatment of heart failure: materials, outcomes and challenges. Acta Biomater 7(1):1-15. doi:10.1016/j.actbio.2010.06.039

94. Johnson TD, Christman KL (2013) Injectable hydrogel therapies and their delivery strategies for treating myocardial infarction. Expert Opin Drug Deliv 10(1):59-72. doi:10.1517/17425247. 2013.739156

95. Wall ST, Walker JC, Healy KE, Ratcliffe MB, Guccione JM (2006) Theoretical impact of the injection of material into the myocardium - a finite element model simulation. Circulation 114(24):2627-2635. doi:10.1161/Circulationaha.106.657270

96. Legner D, Skatulla S, Mbew J, Rama RR, Reddy BD, Sansour C, Davies NH, Franz T (2014) Studying the influence of hydrogel injections into the infarcted left ventricle using the element-free Galerkin method. Int J Numer Methods Biomed Eng 30(3):416-429. doi:10.1002/cnm.2610

97. Ifkovits JL, Tous E, Minakawa M, Morita M, Robb JD, Koomalsingh KJ, Gorman JH, Gorman RC, Burdick JA (2010) Injectable hydrogel properties influence infarct expansion and extent of postinfarction left ventricular remodeling in an ovine model. Proc Natl Acad Sci USA 107(25):11507-11512

98. Kichula ET, Wang H, Dorsey SM, Szczesny SE, Elliott DM, Burdick JA, Wenk JF (2014) Experimental and computational investigation of altered mechanical properties in myocardium after hydrogel injection. Ann Biomed Eng 42(7):1546-1556. doi:10.1007/s10439-013-0937-9

99. Wenk JF, Wall ST, Peterson RC, Helgerson SL, Sabbah HN, Burger M, Stander N, Ratcliffe MB, Guccione JM (2009) A method for automatically optimizing medical devices for treating heart failure: designing polymeric injection patterns. J Biomech Eng 131(12):121011. doi:10.1115/1.4000165

100. Miller R, Davies NH, Kortsmit J, Zilla P, Franz T (2013) Outcomes of myocardial infarction hydrogel injection therapy in the human left ventricle dependent on injectate distribution. Int $\mathrm{J}$ Numer Methods Biomed Eng 29(8):870-884. doi:10.1002/cnm. 2551

101. Kortsmit J, Davies NH, Miller R, Zilla P, Franz T (2013) Computational predictions of improved of wall mechanics and function of the infarcted left ventricle at early and late remodelling stages: comparison of layered and bulk hydrogel injectates. Adv Biomech Appl 1(1):41-55 
102. Kortsmit J, Davies NH, Miller R, Macadangdang JR, Zilla P, Franz T (2013) The effect of hydrogel injection on cardiac function and myocardial mechanics in a computational postinfarction model. Comput Methods Biomech Biomed Eng 16(11):1185-1195. doi:10.1080/10255842.2012.656611

103. Sirry MS, Davies NH, Kadner K, Dubuis L, Saleh MG, Meintjes EM, Spottiswoode BS, Zilla P, Franz T (2015) Micro-structurally detailed model of a therapeutic hydrogel injectate in a rat biventricular cardiac geometry for computational simulations. Comput Methods Biomech Biomed Eng 18(3):325-331. doi:10. 1080/10255842.2013.793765

104. Lee LC, Wall ST, Genet M, Hinson A, Guccione JM (2014) Bioinjection treatment: effects of post-injection residual stress on left ventricular wall stress. J Biomech 47(12):3115-3119. doi:10.1016/j.jbiomech.2014.06.026

105. Lee RJ, Hinson A, Helgerson S, Bauernschmitt R, Sabbah HN (2013) Polymer-based restoration of left ventricular mechanics. Cell Transplant 22(3):529-533. doi:10.3727/096368911X63 7461

106. Lee LC, Wall ST, Klepach D, Ge L, Zhang Z, Lee RJ, Hinson A, Gorman JH 3rd, Gorman RC, Guccione JM (2013) Algisyl-LVR with coronary artery bypass grafting reduces left ventricular wall stress and improves function in the failing human heart. Int J Cardiol 168(3):2022-2028. doi:10.1016/j.ijcard.2013.01.003

107. Göktepe S, Abilez OJ, Kuhl E (2010) A generic approach towards finite growth with examples of athlete's heart, cardiac dilation, and cardiac wall thickening. J Mech Phys Solids 58(10):1661-1680. doi:10.1016/j.jmps.2010.07.003

108. Lee LC, Genet M, Acevedo-Bolton G, Ordovas K, Guccione JM, Kuhl E (2014) A computational model that predicts reverse growth in response to mechanical unloading. Biomech Model Mechanobiol. doi:10.1007/s10237-014-0598-0
109. Genet M, Lee LC, Baillargeon B, Guccione JM, Kuhl E (2015) Modeling pathologies of diastolic and systolic heart failure. Ann Biomed Eng. doi:10.1007/s10439-015-1351-2

110. Rouillard AD, Holmes JW (2014) Coupled agent-based and finite-element models for predicting scar structure following myocardial infarction. Prog Biophys Mol Biol 115(2-3): 235-243. doi:10.1016/j.pbiomolbio.2014.06.010

111. Nam Y-J, Song K, Luo X, Daniel E, Lambeth K, West K, Hill JA, DiMaio JM, Baker LA, Bassel-Duby R (2013) Reprogramming of human fibroblasts toward a cardiac fate. Proc Natl Acad Sci USA 110(14):5588-5593

112. Song K, Nam Y-J, Luo X, Qi X, Tan W, Huang GN, Acharya A, Smith CL, Tallquist MD, Neilson EG (2012) Heart repair by reprogramming non-myocytes with cardiac transcription factors. Nature 485(7400):599-604

113. Miyahara Y, Nagaya N, Kataoka M, Yanagawa B, Tanaka K, Hao H, Ishino K, Ishida H, Shimizu T, Kangawa K (2006) Monolayered mesenchymal stem cells repair scarred myocardium after myocardial infarction. Nat Med 12(4):459-465

114. Amado LC, Saliaris AP, Schuleri KH, John MS, Xie J-S, Cattaneo S, Durand DJ, Fitton T, Kuang JQ, Stewart G (2005) Cardiac repair with intramyocardial injection of allogeneic mesenchymal stem cells after myocardial infarction. Proc Natl Acad Sci USA 102(32):11474-11479

115. Baillargeon B, Costa I, Leach J, Lee L, Genet M, Toutain A, Wenk J, Rausch M, Rebelo N, Acevedo-Bolton G, Kuhl E, Navia J, Guccione J (2015) Human cardiac function simulator for the optimal design of a novel annuloplasty ring with a subvalvular element for correction of ischemic mitral regurgitation. Cardiovasc Eng Tech 6(2):105-116. doi:10.1007/s13239-0150216-Z 